e-ISSN: 2359-5078

\title{
Viabilidade econômico-financeira da cultura do café arábica na região da Alta Mogiana
}

Economic-financial viability of the arabica coffee crop in the region of Alta Mogiana

\author{
Thaís Bianchin Goes ${ }^{1}$; Gressa Amanda Chinelato ${ }^{2 *}$
}

\begin{abstract}
${ }^{1}$ Escola Superior de Agricultura Luiz de Queiroz / Universidade de São Paulo - MBA em Agronegócios Av. Pádua Dias, 11 - $13418-900$ - Piracicaba (SP), Brasil
${ }^{2 *}$ Escola Superior de Agricultura Luiz de Queiroz / Universidade de São Paulo - Doutoranda em Fitopatologia - Av. Pádua Dias, 11 - $13418-900$ - Piracicaba (SP), Brasil <gressa.chinelato@hotmail.com>
\end{abstract}

\section{Resumo}

A região da Alta Mogiana, além de ser tradicional na produção de cafés, se destaca no contexto nacional pela produção de grãos com características sensoriais diferenciadas. O capital investido no cultivo do café (Coffea sp.), que é uma cultura perene, pode permanecer imobilizado por um longo período, portanto, é preciso um planejamento racional antes de investir. O objetivo deste trabalho foi realizar uma análise de viabilidade econômico-financeira, a fim de fornecer elementos para dar bases ao processo de decisão de investir na cafeicultura da Alta Mogiana. Neste trabalho foram analisados dois cenários de produtividade para três diferentes valores para comercialização da saca de café e dois períodos de duração dos projetos. A comparação de cenários mostrou que um incremento de 5,6 sacas na produtividade pode ser um fator determinante para uma lavoura cafeeira ser viável ou não. De acordo com os indicadores econômicos obtidos, o investimento na cafeicultura na região é viável ao considerar uma produtividade média de 34,40 sacas por hectare e um valor médio de venda da saca a $\mathrm{R} \$ 486,85$ ou uma produtividade de 40 sacas por hectare e preço de comercialização da saca acima de $\mathrm{R} \$ 400,00$.

Palavras-chave: cafeicultura, custos, indicadores, investimento, produtividade

\begin{abstract}
The Alta Mogiana region, besides being traditional in the production of coffees, stands out in the national context for the production of grains with differentiated sensorial characteristics. The capital invested in the coffee (Coffea sp.) cultivation, which is a perennial crop, can remain immobilized for a long period, so rational planning is necessary before investing. The objective of this work was to carry out an economicfinancial feasibility analysis, in order to provide elements to give basis to the decision process of investing in Alta Mogiana's coffee-growing. In this work two productivity scenarios were analysed for three different coffee bag prices and two periods length for the projects. The comparison of scenarios showed that an increase of 5.6 sacks in productivity may be a determining factor for a coffee production to be viable or not. According to the economic indicators obtained, the investment in coffee production in the region is feasible considering an average yield of 34.40 bags per hectare and an average sale value of $\mathrm{R} \$ 486.85$ per coffee bag or a yield of 40 bags per hectare and a coffee bag price above $\mathrm{R} \$ 400.00$.
\end{abstract}

Keywords: coffee-growing, costs, indicators, investment, productivity

\section{Introdução}

O cultivo do cafeeiro faz parte da história do Brasil e o hábito de tomar a bebida café está presente no dia a dia do brasileiro. A cafeicultura foi responsável pelo progresso econômico do país no início do século XX e, desde o início do século XIX, o café configura-se como um dos principais produtos de exportação do país. Segundo o Ministério da Agricultura e Pecuária [MAPA], em 2016, o café ocupou a $5^{\text {a }}$ posição no ranking das exportações do agronegócio brasileiro, movimentando um montante de 600,74 milhões dólares (MAPA, 2017).

O Brasil é o maior produtor de café, seguido por Vietnã, Colômbia e Indonésia, e o segundo no ranking dos países que mais consomem café, atrás apenas dos
Estados Unidos (Organização Internacional do Café, 2017). Na safra de 2016, a produção no Brasil foi de 51,37 milhões de sacas beneficiadas, das quais $84,5 \%$ são de café arábica (Coffea arabica L.) e 15,5\% de café canéfora (Coffea canephofora L.), ocupando uma área de 2,2 milhões de hectares cuja produtividade média estimada é de 26,33 sacas por hectare (CONAB, 2017).

Devido a sua extensão territorial, o país apresenta uma variedade de microclimas, relevo, altitude, latitude e tipos de solo. As combinações desses fatores proporcionam a obtenção de variados padrões de qualidade e aromas entre as duas espécies mais cultivadas, arábica e canéfora (conilon ou robusta), ambas apresentam uma diversidade de variedades e linhagens. 
O café arábica é uma espécie originalmente arbustiva, natural da Etiópia e apresenta uma complexidade sensorial maior que o café canéfora. No Brasil, é cultivado em altitudes acima de 800 metros e é predominante nas lavouras de Minas Gerais, São Paulo, Paraná, Bahia, Rio de Janeiro e nas montanhas do Espírito Santo.

Andrade e outros autores (2009) realizaram o estudo de viabilidade econômica da cafeicultura em cinco regiões produtoras no Brasil. Os autores concluíram que investir em cafeicultura nas principais regiões produtoras do país é menos rentável na grande maioria dos casos quando comparada à taxa Selic e ainda relatam a importância de da análise da viabilidade econômica para cada situação. Oliveira e Veneziano (2001) verificaram no estado de Rondônia que os preços do café no período estudado não pagava os sistemas de produção estudados. Arêdes e Pereira (2008) observaram que os sistemas produtivos foram economicamente viáveis para produção de 25 e 40 sacas por hectare, embora a atividade possua elevado nível de risco, especialmente o sistema com baixa produtividade.

No estado de São Paulo, a Alta Mogiana é uma região tradicional na produção de café que se destaca na produção de grãos com características sensoriais diferenciadas. Além de a região ser reconhecida como Indicação Geográfica [IG], na espécie Indicação de Procedência [IP] (MAPA, 2017), seu relevo possibilita a mecanização da lavoura, favorecendo a produtividade e reduzindo os custos com mão de obra.

Ainda que em uma área favorável, a cultura do cafeeiro envolve muitas incertezas e riscos, sobretudo relacionadas ao mercado e aos fatores climáticos e biológicos. Essas variáveis, de incertezas e riscos, afetam os preços de comercialização, que exercem influência na viabilidade do retorno econômico-financeiro da atividade e, portanto, na renda do cafeicultor.

Considerando os dados técnicos e mercadológicos referentes a região, e para dar suporte ao agricultor, este trabalho teve por objetivo analisar a viabilidade econômica da produção de café arábica na Alta Mogiana. Os resultados visam dar bases ao processo de decisão de investir na cafeicultura favorecendo a racionalização da escolha.

\section{Material e Métodos}

A análise de viabilidade econômico-financeira de um projeto fornece informações para a tomada de decisões nos distintos cenários que compõe o mercado. $\mathrm{Na}$ elaboração de um projeto, a construção correta de um fluxo de caixa é uma das etapas mais importantes, uma vez que os indicadores econômicos de viabilidade derivam desse fluxo. Os fluxos de caixa são valores monetários que representam as saídas e entradas dos recursos e produtos por unidade de tempo, compondo um projeto de investimento. Estes são formados por fluxos de entrada (receitas efetivas) e fluxos de saída (dispêndios efetivos ou custos), cuja diferença é denominada de fluxo líquido (Noronha, 1987).

Para avaliar a rentabilidade e a viabilidade econômica, a partir do fluxo de caixa, utilizam-se indicadores de viabilidade econômica, ou seja, resultados de cálculos que indicam se um projeto é rentável, lucrativo e se compensa em relação a outras alternativas. Destacamse o Valor Presente Líquido [VPL], a Taxa Interna de Retorno [TIR] e o Período de "Payback" [PB].

Conceitualmente, o Valor Presente Líquido [VPL] consiste em transferir para o momento atual todas as variações de caixa esperadas, descontá-las a uma determinada taxa de juros, e somá-las algebricamente. Para o cálculo do VPL foi utilizada a eq. (1) (Brigham e Houston, 1999):

$$
V P L=\sum_{t=0}^{n} \frac{F_{t}}{(1+k)^{t}}
$$

onde, VPL: é o valor presente líquido, Investimento Inicial: é o investimento de capital na data zero, $\mathrm{FC}_{\mathrm{t}}$ : representa o retorno na data, t: é o período do fluxo de caixa, n: é o prazo de análise do projeto; e, k: custo de capital do projeto.

O investimento inicial neste trabalho compõe os custos com implantação e as variáveis no ano zero. Quando o VPL é maior que zero, o projeto é viável. Se o VPL é menor que zero, o projeto é inviável. Caso o VPL seja igual a zero, a decisão de investir no projeto é neutra. Quanto maior seu valor, mais interessante é o projeto do ponto de vista econômico.

A Taxa Interna de Retorno [TIR] de um projeto é a taxa que iguala o valor presente líquido do fluxo de caixa a zero, que torna o $\mathrm{VPL}=0$, caracterizando a taxa de remuneração do capital investido, com o objetivo de encontrar o retorno do investimento. Esse cálculo é dado pela eq. (2) (Brigham e Houston, 1999):

$$
\sum_{\mathrm{t}=0}^{\mathrm{n}} \frac{\mathrm{FC}_{\mathrm{t}}}{(1+\mathrm{TIR})^{\mathrm{t}}}=0
$$

onde, TIR: é a taxa interna de retorno, $\mathrm{FC}_{\mathrm{t}}$ : representa o retorno na data, t: é o período do fluxo de caixa; e, n: é o prazo de análise do projeto.

A TIR é, posteriormente, comparada com a taxa mínima de atratividade [TMA], que representa o custo de oportunidade do capital investido do projeto, a fim de verificar o desempenho do mesmo. Caso a TIR seja maior que a TMA, o investimento é atrativo, ou seja, viável. Se ambas as taxas forem iguais, o investimento 
está economicamente numa situação de indiferença. E se a TIR for menor, o investimento é inviável.

O "Payback" [PB] ou tempo de recuperação do capital determina o prazo (tempo) em que o capital aplicado em um projeto será recuperado, ou seja, retornará ao caixa do investidor (eq. 3) (Brigham e Houston, 1999). O PB pode ser calculado com base no fluxo de caixa simples ("payback" simples) ou no fluxo de caixa descontado ("payback" descontado), que inclui uma taxa de juros. A equação para o cálculo do PB simples ou descontado é a mesma, a diferença está no fluxo de caixa a ser utilizado. Quanto menor o período de recuperação do capital investido, maior a liquidez do projeto e menor o seu risco.

$\mathrm{PB}=$ Antes da recuperação total $+\frac{\text { Custo não recuperado no início do ano }}{\mathrm{FC}}$

onde, PB: é o "payback", FC: fluxo de caixa durante o ano.

Quando o projeto tem uma amplitude de tempo prolongada, faz-se necessário relacionar os valores futuros com valores presentes, por meio de uma taxa de juros, que pode ser a própria TMA.

A Taxa Mínima de atratividade [TMA] é uma taxa de juros que representa o percentual mínimo que um investidor se propõe a ganhar ou ao máximo que um individuo se propõe a pagar ao realizar um financiamento. A TMA é estimada nas principais taxas de juros praticada pelo mercado, como a Taxa Básica Financeira [TMF], Taxa Referencial [TR], Taxa de Juros de Longo Prazo [TJLP], Sistema Especial de Liquidação e Custódia [SELIC]. Tais taxas são taxas nominais, isto é, seus valores não consideram o efeito da inflação no período.

Para determinar um valor para TMA, pode utilizar-se uma taxa de juros nominal ou de juros real. A taxa de juros nominal corresponde ao valor da taxa contratada ou declarada em uma operação financeira. E a taxa de juros reais consiste na taxa de juros nominais descontando a inflação. Esse cálculo é dado pela eq. (4):

$$
\text { Juros Reais }=\frac{(1+\text { juros nominais })}{(1+\text { inflação })}-1
$$

Para o cálculo Receita Bruta [RB] anual, utilizou-se a eq. (5):

$$
\mathrm{RB}=\text { Pm } x \text { Prod }
$$

onde, RB: é a receita bruta, Pm: é o preço médio, Prod: é a produtividade média.

\section{Procedimentos de análise e fonte de dados}

Os fluxos de caixa para a produção de café arábica na região da Alta Mogiana foram elaborados a partir da obtenção de coeficientes técnicos, custos de produção e investimentos por meio de consulta a artigos, anuários como Agrianual (Agrianual, 2016), da produtividade da Companhia Nacional de Abastecimento [CONAB] e série de preços mensais do café do período de janeiro de 2006 a abril de 2017 fornecido pelo Centro de Estudos Avançados em Economia Aplicada [CEPEA].

Segundo Matiello et al. (2015) há dois tipos de custo nas propriedades cafeeiras: os custos gerais e os específicos. O primeiro refere-se à administração, manutenções diversas, benfeitorias, energia, impostos, etc. O outro se refere aos custos relacionados à formação do cafezal (fase improdutiva) e ao manejo anual das lavouras adultas (fase produtiva), envolvendo as despesas anuais na condução dos tratos da lavoura, na colheita e no preparo do café. Contudo os custos de produção de café são variáveis, dependendo da região, da propriedade, das características edafoclimáticas da área, do sistema operacional (manual ou mecanizado), do manejo, do sistema de plantio e o tipo de produção adotada.

Os custos gerais foram denominados custos fixos e os custos específicos separados em custos variáveis e de implantação (Tabelas 1 e 2). A soma desses valores originou o custo total. As despesas referentes a aquisição de máquinas, implementos e construção de infraestrutura, bem como o custo de oportunidade e depreciação não foram considerados, uma vez que a análise foi realizada em um cenário hipotético de um hectare. Dessa maneira, o estudo pode ser utilizado e adaptado aos diferentes perfis de produtores, de acordo com sua área de plantio, bens, necessidades e tipo de produção.

Para determinar a produtividade da região de Franca, estado de São Paulo, utilizaram-se os dados do Agrianual 2016 que apresenta os dados do ano de 2015 para café arábica. No anuário consta três valores para a produtividade. Um valor médio de 34,4 sacas $\mathrm{ha}^{-1}$, outro para a primeira carga ou produção da planta, de 20 sacas ha ${ }^{-1}$, e um terceiro para os demais anos, no valor de 40 sacas $\mathrm{ha}^{-1}$. O valor menor para o primeiro ano de produção efetiva da planta justifica-se pelo fato do cafeeiro estar em "fase de crescimento". O cafeeiro por ser uma planta que apresenta uma bienalidade, ou seja, em um ano produz mais, no ano seguinte produz menos, por isso, os valores de produtividade foram a média desses anos de produção. $O$ valor da produtividade média de 34,4 sacas ha-1 informado pelo Agrianual, está acima da média brasileira de 26,33 sacas ha-1, segundo a CONAB (2017). Em conversas informais com produtores, agrônomos e técnicos que atuam na região da Alta Mogiana, constatou-se plausível considerar uma produtividade média de 40 sacas $\mathrm{ha}^{-1}$. Assim foram utilizados os valores de 20 sacas ha $\mathrm{ha}^{-1}$ para os dois primeiros anos após a instalação da cultura e utilizou para os demais anos 34,4 e 40 sacas ha $^{-1}$, dessa forma, foram estudados dois cenários de produtividade de café (Tabela 3). 
Tabela 1. Custos específicos (implantação, variáveis e fixos) da produção de café mecanizado na região da Alta Mogiana na fase improdutiva

\begin{tabular}{|c|c|c|c|c|c|c|c|c|}
\hline \multirow{3}{*}{ Descrição } & \multirow{3}{*}{ Especificação } & \multirow{3}{*}{$\begin{array}{l}\text { Valor } \\
\text { Unitário }\end{array}$} & \multicolumn{6}{|c|}{ Fase Improdutiva (Formação) } \\
\hline & & & \multicolumn{2}{|c|}{ Ano 0} & \multicolumn{2}{|l|}{ Ano 1} & \multicolumn{2}{|c|}{ Ano 2} \\
\hline & & & Qtde & Valor & Qtde & Valor & Qtde & Valor \\
\hline \multicolumn{9}{|l|}{ A- Implantação } \\
\hline Aração & $\mathrm{HM}^{1}$ & 91 & 4 & 365 & - & - & - & - \\
\hline Calagem & $\mathrm{HM}$ & 88 & 2 & 176 & - & - & - & - \\
\hline Gradeação Leve & $\mathrm{HM}$ & 93 & 2 & 223 & - & - & - & - \\
\hline Conservação do solo & $\mathrm{HM}$ & 113 & 1 & 79 & - & - & - & - \\
\hline Dessecação com herbicida & $\mathrm{HM}$ & 89 & 0 & 18 & - & - & - & - \\
\hline Sulcação & $\mathrm{HM}$ & 88 & 4 & 307 & - & - & - & - \\
\hline Distribuição Calcário Sulcos & $\mathrm{HM}$ & 94 & 2 & 141 & - & - & - & - \\
\hline Distribuição Fertilizantes & $\mathrm{HM}$ & 94 & 2 & 141 & - & - & - & - \\
\hline Incorporação de Fertilizante no Sulco & HM & 87 & 2 & 147 & - & - & - & - \\
\hline Transportes das Mudas & $\mathrm{HM}$ & 74 & 2 & 111 & - & - & - & - \\
\hline Plantio & $\mathrm{HD}^{2}$ & 39 & 25 & 975 & - & - & - & - \\
\hline Replantio & HD & 39 & 5 & 195 & 2 & 78 & - & - \\
\hline Subtotal A - Custos Implantação & & & & 2878 & & 78 & & \\
\hline \multicolumn{9}{|l|}{ B- Custos Variáveis } \\
\hline \multicolumn{9}{|l|}{ B1- Manutenção } \\
\hline Capina/Desbrota & $\mathrm{HD}$ & 39 & 20 & 780 & 15 & 585 & 5 & 195 \\
\hline Roçada & $\mathrm{HM}$ & 77 & 5 & 383 & 11 & 812 & 11 & 812 \\
\hline Calagem & $\mathrm{HM}$ & 88 & - & - & - & - & 2 & 158 \\
\hline Calagem & HD & 39 & - & - & - & - & 2 & 86 \\
\hline Adubação Manual & $\mathrm{HD}$ & 39 & 4 & 156 & 4 & 156 & - & - \\
\hline Adubação Mecanizada & $\mathrm{HM}$ & 88 & & - & - & - & 6 & 527 \\
\hline Aplicação Defensivo Manual & HD & 39 & 5 & 195 & 5 & 195 & - & - \\
\hline Aplicação Defensivo Mecanizada & $\mathrm{HM}$ & 110 & 2 & 165 & 2 & 165 & 6 & 662 \\
\hline Aplicação Herbicida Pré (linha) & $\mathrm{HD}$ & 39 & 2 & 59 & 3 & 117 & - & - \\
\hline Aplicação Herbicida Pré (entre-linha) & $\mathrm{HM}$ & 82 & - & - & - & - & 6 & 482 \\
\hline \multicolumn{9}{|l|}{ B2- Colheita } \\
\hline Colheita Manual & $\mathrm{HD}$ & 59 & - & - & - & - & 16 & 936 \\
\hline Colheita Mecanizada & $\mathrm{HM}$ & 163 & - & - & - & - & - & - \\
\hline Secagem & $\mathrm{HD}$ & 59 & - & - & - & - & 4 & 211 \\
\hline Arruação/ Varrição & HD & 59 & - & - & - & - & 7 & 380 \\
\hline Beneficiamento & $\mathrm{R} \$ \mathrm{sc}^{-1}$ & 7 & - & - & - & - & 20 & 140 \\
\hline Transporte Interno & $\mathrm{HM}$ & 74 & - & - & - & - & 2 & 111 \\
\hline \multicolumn{9}{|l|}{ B3- Insumos e Materiais } \\
\hline Calcário & $\mathrm{R} \$ \mathrm{t}^{-1}$ & 110 & 3 & 363 & - & - & 1 & 110 \\
\hline Superfosfato Simples & $\mathrm{R} \$ \mathrm{~kg}^{-1}$ & 1 & 800 & 568 & - & - & 220 & 156 \\
\hline Nitrato de Amônio & $\mathrm{R} \$ \mathrm{~kg}^{-1}$ & 1 & - & - & - & - & 300 & 342 \\
\hline Fertilizante $20-00-20$ & $\mathrm{R} \$ \mathrm{~kg}^{-1}$ & 1 & 500 & 560 & 1000 & 1120 & 1500 & 1680 \\
\hline Herbicida & $\mathrm{R} \$ \mathrm{~L}^{-1}$ & & - & 366 & & 290 & & 91 \\
\hline Acaricida/Inseticida & $\mathrm{R} \$ \mathrm{~L}^{-1}$ & & - & 108 & & 144 & & 237 \\
\hline Fungicida & $\mathrm{R} \$ \mathrm{~kg}^{-1}$ & & - & - & & - & & 103 \\
\hline Oxicloreto de Cobre & $\mathrm{R} \$ \mathrm{~kg}^{-1}$ & 17 & 2 & 33 & 6 & 99 & 6 & 99 \\
\hline Espalhante Adesivo & $\mathrm{R} \$ \mathrm{~L}^{-1}$ & 16 & 2 & 32 & 3 & 49 & 4 & 65 \\
\hline Óleo Mineral & $\mathrm{R} \$ \mathrm{~L}^{-1}$ & 11 & - & - & - & - & 2 & 22 \\
\hline Mudas & $\mathrm{R} \$$ unidade ${ }^{-1}$ & 1 & 4800 & 6960 & 480 & 696 & - & - \\
\hline Sacarias & $\mathrm{R} \$$ unidade $^{-1}$ & 7 & - & - & - & - & 20 & 130 \\
\hline Subtotal B - Custos Variáveis & & & & 10728 & & 4427 & & 7733 \\
\hline \multicolumn{9}{|l|}{ C-Custos Fixos } \\
\hline Viagens & $\mathrm{R} \$ \mathrm{ha}^{-1}$ & 245 & 1 & 245 & 1 & 245 & 1 & 245 \\
\hline Assistência Técnica & $\mathrm{R} \$ \mathrm{ha}^{-1}$ & 192 & 1 & 192 & 1 & 192 & 1 & 192 \\
\hline Mão de obra Administrativa & $\mathrm{R} \$ \mathrm{ha}^{-1}$ & 565 & 1 & 565 & 1 & 565 & 1 & 565 \\
\hline Contabilidade/Escritório & $\mathrm{R} \$ \mathrm{ha}^{-1}$ & 145 & 1 & 145 & 1 & 145 & 1 & 145 \\
\hline Luz/Telefone & $\mathrm{R} \$ \mathrm{ha}^{-1}$ & 217 & 1 & 217 & 1 & 217 & 1 & 217 \\
\hline $\begin{array}{l}\text { Conservação/Depreciação/ } \\
\text { Benfeitoria }\end{array}$ & $\mathrm{R} \$ \mathrm{ha}^{-1}$ & 34 & 1 & 34 & 1 & 34 & 1 & 34 \\
\hline Subtotal C - Custos Fixos & & & & 1398 & & 1398 & & 1398 \\
\hline Total A+B+C & & & & 15003 & & 5903 & & 9130 \\
\hline
\end{tabular}

Fonte: Agrianual (2016)

Nota: ${ }^{1}$ HM: Hora-máquina; ${ }^{2}$ HD: Homem-dia; Qtde: Quantidade 
Tabela 2. Custos específicos (implantação, variáveis e fixos) da produção de café mecanizado na região da Alta Mogiana na fase produtiva

\begin{tabular}{|c|c|c|c|c|c|c|}
\hline \multirow{3}{*}{ Descrição } & \multirow{3}{*}{ Especificação } & \multirow{3}{*}{$\begin{array}{l}\text { Valor } \\
\text { Unitário }\end{array}$} & \multicolumn{4}{|c|}{ Fase Produtiva } \\
\hline & & & \multicolumn{2}{|c|}{ Ano 3} & \multicolumn{2}{|c|}{ Ano 4 ao 20} \\
\hline & & & Quantidade & Valor & Quantidade & Valor \\
\hline \multicolumn{7}{|l|}{ A- Implantação } \\
\hline Aração & $\mathrm{HM}^{1}$ & 91 & - & - & - & - \\
\hline Calagem & $\mathrm{HM}$ & 88 & - & - & - & - \\
\hline Gradeação Leve & $\mathrm{HM}$ & 93 & - & - & - & - \\
\hline Conservação do solo & $\mathrm{HM}$ & 113 & - & - & - & - \\
\hline Dessecação com herbicida & $\mathrm{HM}$ & 89 & - & - & - & - \\
\hline Sulcação & $\mathrm{HM}$ & 88 & - & - & - & - \\
\hline Distr. Calcário Sulcos & $\mathrm{HM}$ & 94 & - & - & - & - \\
\hline Distr. Fertilizantes & $\mathrm{HM}$ & 94 & - & - & - & - \\
\hline Incorp. de Adubo no Sulco & $\mathrm{HM}$ & 87 & - & - & - & - \\
\hline Transportes das Mudas & $\mathrm{HM}$ & 74 & - & - & - & - \\
\hline Plantio & $\mathrm{HD}^{2}$ & 39 & - & - & - & - \\
\hline Replantio & HD & 39 & - & - & - & - \\
\hline \multicolumn{7}{|l|}{ Subtotal A - Custos Implantação } \\
\hline \multicolumn{7}{|l|}{ B- Custos Variáveis } \\
\hline \multicolumn{7}{|l|}{ B1- Manutenção } \\
\hline Capina/ Desbrota & HD & 39 & 5 & 195 & 5 & 195 \\
\hline Roçada & $\mathrm{HM}$ & 77 & 11 & 812 & 11 & 812 \\
\hline Calagem & $\mathrm{HM}$ & 88 & 2 & 158 & 2 & 158 \\
\hline Calagem & HD & 39 & 2 & 86 & 2 & 86 \\
\hline Adubação Manual & HD & 39 & - & - & - & - \\
\hline Adubação Mecanizada & $\mathrm{HM}$ & 88 & 6 & 527 & 6 & 527 \\
\hline Aplic. Defens. Manual & HD & 39 & - & - & - & - \\
\hline Aplic. Defens. Mecanizada & $\mathrm{HM}$ & 110 & 6 & 662 & 6 & 662 \\
\hline Aplic. Herb. Pré (linha) & HD & 39 & - & - & - & - \\
\hline Aplic. Herb. Pré (entre-linha) & $\mathrm{HM}$ & 82 & 6 & 482 & 6 & 482 \\
\hline \multicolumn{7}{|l|}{ B2- Colheita } \\
\hline Colheita Manual & $\mathrm{HD}$ & 59 & 2 & 117 & 2 & 117 \\
\hline Colheita Mecanizada & $\mathrm{HM}$ & 163 & 5 & 813 & 5 & 813 \\
\hline Secagem & HD & 59 & 7 & 421 & 7 & 421 \\
\hline Arruação/Varrição & HD & 59 & 15 & 848 & 15 & 848 \\
\hline Beneficiamento & $\mathrm{R} \$ \mathrm{sc}^{-1}$ & 7 & 40 & 280 & 40 & 280 \\
\hline Transporte Interno & $\mathrm{HM}$ & 74 & 3 & 221 & 3 & 221 \\
\hline \multicolumn{7}{|l|}{ B3- Insumos e Materiais } \\
\hline Calcário & $\mathrm{R} \$ \mathrm{t}^{-1}$ & 110 & 2 & 165 & 2 & 165 \\
\hline Superfosfato Simples & $\mathrm{R} \$ \mathrm{~kg}^{-1}$ & 1 & 330 & 234 & 330 & 234 \\
\hline Nitrato de Amônio & $\mathrm{R} \$ \mathrm{~kg}^{-1}$ & 1 & 300 & 342 & 300 & 342 \\
\hline Fórmula 20-00-20 & $\mathrm{R} \$ \mathrm{~kg}^{-1}$ & 1 & 2000 & 2240 & 2000 & 2240 \\
\hline Herbicida & $\mathrm{R} \$ \mathrm{~L}^{-1}$ & & & 91 & & 91 \\
\hline Acaricida/Inseticida & $\mathrm{R} \$ \mathrm{~L}^{-1}$ & & & 309 & & 309 \\
\hline Fungicida & $\mathrm{R} \$ \mathrm{~kg}^{-1}$ & & & 145 & & 145 \\
\hline Oxicloreto de Cobre & $\mathrm{R} \$ \mathrm{~kg}^{-1}$ & 17 & 6 & 99 & 6 & 99 \\
\hline Espalhante Adesivo & $\mathrm{R} \$ \mathrm{~L}^{-1}$ & 16 & 5 & 81 & 5 & 81 \\
\hline Óleo Mineral & $\mathrm{R} \$ \mathrm{~L}^{-1}$ & 11 & 2 & 22 & 2 & 22 \\
\hline Mudas & $\mathrm{R} \$$ unidade $^{-1}$ & 1 & - & - & - & - \\
\hline Sacarias & $\mathrm{R} \$$ unidade $\mathrm{e}^{-1}$ & 7 & 40 & 260 & 40 & 260 \\
\hline Subtotal B - Custos Variáveis & & & & 9609 & & 9609 \\
\hline \multicolumn{7}{|l|}{ C- Custos Fixos } \\
\hline Viagens & $\mathrm{R} \$ \mathrm{ha}^{-1}$ & 245 & 1 & 245 & 1 & 245 \\
\hline Assistência Técnica & $\mathrm{R} \$ \mathrm{ha}^{-1}$ & 192 & 1 & 192 & 1 & 192 \\
\hline M.O. Administrativa & $\mathrm{R} \$ \mathrm{ha}^{-1}$ & 565 & 1 & 565 & 1 & 565 \\
\hline Contabilidade/ Escritório & $\mathrm{R} \$ \mathrm{ha}^{-1}$ & 145 & 1 & 145 & 1 & 145 \\
\hline Luz/ Telefone & $\mathrm{R} \$ \mathrm{ha}^{-1}$ & 217 & 1 & 217 & 1 & 217 \\
\hline Conservação/Depreciação/Benfeitorias & $\mathrm{R} \$ \mathrm{ha}^{-1}$ & 34 & 1 & 34 & 1 & 34 \\
\hline Subtotal C-Custos Fixos & & & & 1398 & & 1398 \\
\hline Total $\mathrm{A}+\mathrm{B}+\mathrm{C}$ & & & & 11007 & & 11007 \\
\hline
\end{tabular}

Fonte: Agrianual (2016)

Nota: ${ }^{1}$ HM: Hora-máquina; ${ }^{2}$ HD: Homem-dia 
Tabela 3. Cenários de produtividade de café para os dois primeiros anos após a instalação e para o ano 3 ao ano 20

\begin{tabular}{lcr}
\hline & Cenário 1 & Cenário 2 \\
\hline & Produtividade $\left(\mathrm{sc} \mathrm{ha}^{-1}\right)$ \\
Ano 2 & 20,0 & 20,0 \\
Ano 3 a 20 & 34,4 & 40,0 \\
\hline
\end{tabular}

Fonte: Agrianual (2016)

Para determinar o preço da saca de café de 60 $\mathrm{kg}$ utilizou a série histórica do Centro de Estudos Avançados em Economia Aplicada [CEPEA] dos preços médios mensais pagos aos produtores para a região da Alta Mogiana do período de janeiro 2006 a abril de 2017. Os valores mensais foram deflacionados pelo IGP- DI (FGV), para a data base de abril de 2017. Assim, o preço médio recebido pela saca foi de $\mathrm{R} \$ 486,58$, o preço por saca mínimo e máximo foram de $\mathrm{R} \$ 300,67$ e $\mathrm{R} \$ 749,56$, respectivamente (Tabela 4). Os preços deflacionados foram divididos em frequências de preços e a maior porcentagem de frequência está na faixa de $\mathrm{R} \$ 450,00$ a $\mathrm{R} \$ 475,00$ (Figura 1).
Tabela 4. Preços da saca de café para a região da Alta Mogiana do período de janeiro de 2006 a abril de 2017

\begin{tabular}{lr}
\hline \multicolumn{1}{c}{ Item } & \multicolumn{1}{c}{ Valor } \\
\hline & $-----\mathrm{R} \$$ sc $^{-1}-----$ \\
Preço Médio Real & 486,58 \\
Preço Máximo & 749,56 \\
Preço Mínimo & 300,67 \\
Amplitude dos preços & 448,89 \\
Desvio Padrão & 88,23 \\
Desvio Padrão médio & 62,76 \\
\hline
\end{tabular}

Fonte: CEPEA (2017)

Os preços mensais médios deflacionados foram agrupados em intervalos de 25 unidades, a começar pelo menor valor, e ordenados em um histograma, a fim de determinar os intervalos mais e menos frequentes dos preços médios de café no período. $\mathrm{O}$ intervalo no qual o preço da saca de café varia de $\mathrm{R} \$ 450,00$ a $\mathrm{R} \$ 475,00$, o que corresponde a $17,8 \%$ dos valores médios mensais, ou seja, a maior parte dos preços médios mensais do período de janeiro de 2006 a abril de 2017 (Figura 1).

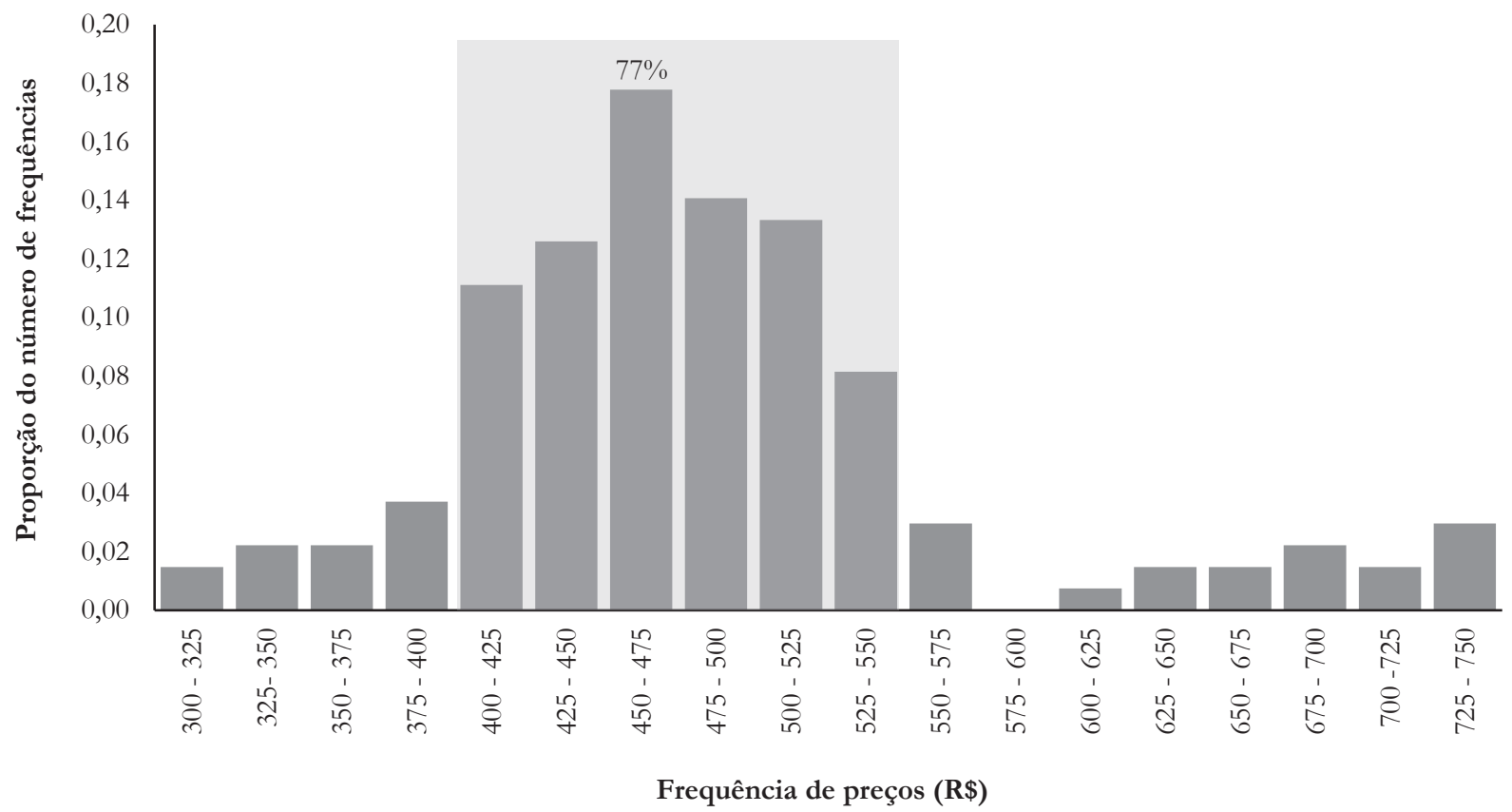

Figura 1. Frequência relativa dos preços reais médios recebidos pelos produtores na região da Alta Mogiana do período de janeiro de 2006 a abril de 2017

Fonte: CEPEA (2017)

Em 14,1\% dos meses os preços ficaram entre $\mathrm{R} \$$ 475,00 e R\$500,00, foi nesse intervalo que encontrou o preço médio para o período, no valor de $\mathrm{R} \$ 486,58$. Percebeu, também, que houve uma maior concentração de valores no intervalo entre $\mathrm{R} \$ 400,00$ e $\mathrm{R} \$ 550,00$, ou seja, em $77 \%$ dos meses o valor médio da saca de café.
Para o calculo do fluxo de caixa foram considerados três valores para a saca de café: preço médio de R $\$ 486,58$ (II) e os valores limítrofes, maior e menor, dentro do intervalo que concentra $77 \%$ dos preços mais frequentes pagos aos produtores entre janeiro de 2006 e abril de 2017, ou seja, $\mathrm{R} \$ 400,00$ (I) e $\mathrm{R} \$ 550,00$ (III). 


\section{Resultados e Discussão}

Os valores da saca de café utilizados para o cálculo do fluxo de caixa ( $\mathrm{R} \$ 400,00$ - I, $\mathrm{R} \$ 486,58$ - II e $\mathrm{R} \$$ 550,00 - III) foram combinados com a produtividade dos cenários 1 e 2 (Tabela 3). Os resultados foram diferentes valores de receita bruta para a elaboração do
Fluxo de Caixa, esses custos para os diferentes anos foram obtidos pelo Agrianual (2016) (Tabela 5). A receita bruta representa o valor monetário resultante da venda das sacas de café produzidas e beneficiadas, e também, foi utilizada a produtividade de sacas de café por hectare.

Tabela 5. Fluxo de caixa resumido para Cenário 1: produtividade de $20,0 \mathrm{sc} \mathrm{ha}^{-1}$ no ano 2 e $34,4 \mathrm{sc} \mathrm{ha}^{-1}$ para até os 20 anos de cultivo, utilizando o valor de $\mathrm{R} \$ 486,58$ para a saca de café

\begin{tabular}{|c|c|c|c|c|c|}
\hline \multirow{2}{*}{ Descrição } & \multicolumn{5}{|c|}{ Anos } \\
\hline & 0 & 1 & 2 & 3 & 4 a 20 \\
\hline & - & 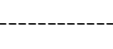 & $\mathrm{R} \$$----- & -------- & --------- \\
\hline Receita Bruta & 0 & 0 & 9.732 & 16.738 & 16.738 \\
\hline Custos (Implantação+ Fixos + Variáveis) & 15.003 & 5.903 & 9.130 & 11.007 & 11.007 \\
\hline Impostos (Funrural - 2,3\% receita bruta) & & & 224 & 385 & 385 \\
\hline Saldo/ Fluxo de Caixa Final & -15.003 & -5.903 & 377 & 5.346 & 5.346 \\
\hline Fluxo de Caixa Acumulado & -15.003 & -20.906 & -20.529 & -15.182 & -9.836 \\
\hline Fluxo de Caixa Descontado $[\mathrm{FCD}]$ (juros = TMA) & -15.003 & -5.528 & 331 & 4.390 & 4.111 \\
\hline Fluxo de Caixa Descontado Acumulado [FCDA] & -15.003 & -20.531 & -20.200 & -15.810 & -11.699 \\
\hline
\end{tabular}

Fonte: Agrianual (2016)

Como a análise foi realizada para uma situação hipotética e referencial, para uma área de um hectare, o imposto de renda não entrou no fluxo de caixa, uma vez que o valor dos rendimentos (receita bruta) foi inferior a alíquota mínima. Porém, considerou-se o Funrural no valor de $2,3 \%$ sobre a receita bruta. A alíquota do imposto de renda a ser descontada dos rendimentos não foi considerada nesta análise.

Devido à sensibilidade e importância do tempo de duração de projetos de investimentos sobre sua rentabilidade, levou-se em consideração um fluxo de caixa para um horizonte de tempo de 15 e para 20 anos, considerando a vida útil das plantas e o surgimento de variedades mais produtivas e menos suscetíveis a algumas pragas e doenças e, portanto, da necessidade de uma possível renovação da lavoura.

Em relação a taxa de juros, para realizar as análises foram utilizadas duas taxas de juros, sendo 11,15\% referente a taxa de juros Sistema Especial de Liquidação e Custódia [Selic] divulgada pelo Comitê de Política Monetária [Copom] do Banco Central e a outra taxa de $6,79 \%$ que representa a taxa de juros reais, em que foi descontada a inflação do período do valor da Selic, também informada pelo Copom, para abril de 2017.

Com base no fluxo de caixa foram calculados o VPL e TIR com valores de TMA de 11,15\% e 6,79\%, bem como o período de "payback" simples [PBS] e descontado. O PBS foi baseado no fluxo de caixa desconsiderando a TMA, enquanto o PBD considerou os diferentes valores para a TMA.

Em um horizonte de 15 anos, analisando o cenário 1 (I) utilizando ambas as taxas médias de atratividade de $6,79 \%$ e de $11,15 \%$, o investimento não foi viável, pois gerou um VPL negativo. A TIR foi menor que a taxa mínima de atratividade, o que o tornou não atrativo. Além disso, o PBD a 11,15\% não recuperou o investimento inicial. Assim, uma produtividade média de 34,4 sacas por hectare comercializada por $\mathrm{R} \$ 400,00$ tornou o projeto inviável. Porém, com um incremento de 5,6 sacas por hectare, o projeto se tornou viável, cenário 2 (I) ('Tabelas 6).

Se essa mesma produtividade de 34,4 sacas por hectare for vendida por um valor de $\mathrm{R} \$ 486,58$ a saca, cenário 1(II), a viabilidade ao projeto estará garantida, independente se a vida-útil da lavoura for de 15 ou 20 anos. O PB nesse caso oscila entre 5 anos e 10 meses a 8 anos e 10 meses (Tabela 6 e 7).

Ainda considerando a mesma produtividade de 34,4 sacas por hectare, se for comercializada a $\mathrm{R} \$ 486,58$, como ilustra o cenário 1(II), apresentará melhores resultados dos indicadores de viabilidade econômica e o PB ocorrerá em um prazo menor que uma produtividade de 40 sacas por hectare vendida a um valor mais $R \$ 400,00$, cenário 2 (I). 
Tabela 6. Indicadores de viabilidade econômica da produção de café com o tempo de 15 anos para vida útil do cafezal para região da Alta Mogiana

\begin{tabular}{|c|c|c|c|c|c|c|}
\hline \multirow{4}{*}{ Indicadores } & \multicolumn{6}{|c|}{ Duração 15 anos } \\
\hline & \multicolumn{3}{|c|}{ Cenário 1 (sc/ha) } & \multicolumn{3}{|c|}{ Cenário 2 (sc/ha) } \\
\hline & (I) & (II) & (III) & (I) & (II) & (III) \\
\hline & $\mathrm{R} \$ 400,00$ & $\mathrm{R} \$ 486,00$ & $\mathrm{R} \$ 550,00$ & $\mathrm{R} \$ 400,00$ & $\mathrm{R} \$ 486,00$ & $\mathrm{R} \$ 550,00$ \\
\hline & \multicolumn{6}{|c|}{ Duração 15 anos } \\
\hline VPL(11,15\%) & $-8.166,00$ & $8.982,00$ & $21.544,00$ & $3.701,00$ & $23.418,00$ & $37.861,00$ \\
\hline VPL $(6,79 \%)$ & $-3.613,00$ & $19.452,00$ & $36.349,00$ & $12.618,00$ & $39.196,00$ & $58.665,00$ \\
\hline \multirow[t]{3}{*}{ TIR } & 4,0 & 17,0 & 24,0 & 14,0 & 25,0 & 32,0 \\
\hline & \multicolumn{6}{|c|}{ Duração 20 anos } \\
\hline & & & & $-\mathrm{R} \$--$ & ----------- & --------------- \\
\hline VPL(11,15\%) & $-6.329,00$ & $13.014,00$ & $27.183,00$ & $7.189,00$ & $29.458,00$ & $45.769,00$ \\
\hline VPL $(6,79 \%)$ & 137,00 & $27.681,00$ & $47.857,00$ & $19.737,00$ & $51.523,00$ & $74.806,00$ \\
\hline TIR & 7,0 & 18,0 & 25,0 & 15,0 & 26,0 & 32,0 \\
\hline
\end{tabular}

Tabela 7. Período de "Payback" simples e descontado para café na região Alta Mogiana

\begin{tabular}{|c|c|c|c|c|c|c|}
\hline \multirow{3}{*}{ Indicador } & \multicolumn{3}{|c|}{ Cenário 1} & \multicolumn{3}{|c|}{ Cenário 2} \\
\hline & (I) & (II) & (III) & (I) & (II) & (III) \\
\hline & $\mathrm{R} \$ 400,00$ & $\mathrm{R} \$ 486,58$ & $\mathrm{R} \$ 550,00$ & $\mathrm{R} \$ 400,00$ & $\mathrm{R} \$ 486,58$ & $\mathrm{R} \$ 550,00$ \\
\hline & -1------ & ----- & $--------t$ & S-------- & 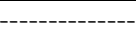 & ---------- \\
\hline Payback simples & $11 \mathrm{a}^{1} 01 \mathrm{~m}^{2}$ & 5a $10 \mathrm{~m}$ & 4a $07 \mathrm{~m}$ & 6a $10 \mathrm{~m}$ & $4 \mathrm{a} 07 \mathrm{~m}$ & 3a $10 \mathrm{~m}$ \\
\hline Payback descontado $(6,79 \%)$ & 19a $09 \mathrm{~m}$ & $7 \mathrm{a} 03 \mathrm{~m}$ & $5 \mathrm{a} 04 \mathrm{~m}$ & $8 \mathrm{a} 10 \mathrm{~m}$ & $5 \mathrm{a} 04 \mathrm{~m}$ & $4 \mathrm{a} 04 \mathrm{~m}$ \\
\hline $\operatorname{PBD}^{3}(11,15)$ & $\mathrm{NRI}^{3}$ & $8 \mathrm{a} 10 \mathrm{~m}$ & $6 \mathrm{a} 01 \mathrm{~m}$ & $11 \mathrm{a} 07 \mathrm{~m}$ & $5 \mathrm{a} 12 \mathrm{~m}$ & $4 \mathrm{a} 09 \mathrm{~m}$ \\
\hline
\end{tabular}

Nota: ${ }^{1}$ anos; ${ }^{2}$ meses; ${ }^{3}$ NRI: Não recupera o investimento

No cenário 2, todas as condições propostas de preço para a saca de café, mostraram-se positivas para viabilidade econômica para a cultura. Quando utilizou o preço da saca de café de $\mathrm{R} \$ 550,00$ e uma produtividade de 40 sacas por hectare, levaria a um menor "payback", variando de até 3 anos e 10 meses. No estudo de Esperancini e Paes (2005), o período de retorno foi de 3,3 anos PBS e 3,9 anos PBD (12\%) na cultura do café em sistema convencional, densidade de plantio de 4.464 plantas por hectare, região de Botucatu, estado de São Paulo. Arêdes e Pereira (2008) encontrou o PBS de 7,6 anos para a região de Minas Gerais na produção de café arábica com produtividade média de 40 sacas por hectare.

Entre as situações analisadas, apenas em uma delas, cenário 1 (I), o projeto se torna inviável. Contudo, fica evidente que os indicadores de viabilidade econômica apresentem sensibilidade quanto a alterações na produtividade e nos preços da saca de café comercializada.

O preço da saca de café sofre influencia de fatores diversos que vão desde a expectativa e a real produção de café no Brasil, bem como oferta e demanda do produto no mercado global, além de especulações e a qualidade do produto. Se por um lado o produtor não consegue prever os preços, ele tem ferramentas em sua mão que lhe permitem aumentar a sua eficiência, sua produtividade, seus ganhos e ter um retorno do investimento.

A comparação de cenários mostrou que um incremento de seis sacas na produtividade pode ser diferença na viabilidade ou não de uma lavoura cafeeira. Ao se tratar de uma cultura perene como o café, o capital investido permanece imobilizado por um longo período, portanto, é preciso planejar com muita cautela e investir em manejos e cultivares que favoreçam a produtividade. Combinar uma produtividade acima da média com um momento de preço favorável para a venda do produto é o melhor cenário.

Para Matiello e outros autores (2015), a cafeicultura atual não pode ser estática como no passado, com o produtor sendo avaliado pela área de cafeeiros que possui. Deve ser dinâmica e empresarial, avaliada anualmente e ajustada de acordo com sua produtividade e rentabilidade, podendo ser reduzida ou ampliada conforme essas análises. 


\section{Conclusão}

A comparação entre os cenários e as análises dos indicadores econômicos propostos demonstra que o acréscimo no preço da saca de café pago aos produtores ou um incremento na produtividade promove um aumento da atratividade de investimento, devido a elevação dos indicadores econômicos e redução do tempo de recuperação do capital investido na produção de café da Alta Mogiana. Todavia, dentro de uma mesma região podem haver variáveis que influenciam, sobretudo, a produtividade, sendo fundamental uma análise individualizada antes de decidir-se por investir na cafeicultura.

\section{Referências}

Agrianual. 2016. Anuário da agricultura brasileira. FNP Consultoria e Agroinformativos, São Paulo. 185$190 \mathrm{p}$.

Andrade, F.T.; de Castro Júnior, L.G.; Costa, C.H.G.; Lima, A.L.R.; Albert, L.H.B. 2009. Análise da viabilidade econômico-financeira da cafeicultura: um estudo nas principais regiões produtoras de café do Brasil. In Anais do Congresso Brasileiro de Custos-ABC.

Banco Central do Brasil [BACEN]. 2017. Taxa Selic dados diários. Disponível em: <http://www.bcb.gov.br/htms/ selic/selicdiarios.asp>. Acesso em 28 maio 2017.

Banco Central do Brasil [BACEN]. 2017. Inflação acumulada período de 12 meses. Disponível em: <http://www.bcb. gov.br/pt-br/\#!/busca/inflacao>. Acesso em 28 maio 2017.

Banco Central do Brasil [BACEN]. 2017. Calculadora. Disponível em: <https://www3.bcb.gov.br/ CALCIDADAO/publico/exibirFormCorrecaoValores. do?method=exibirFormCorrecaoValores $>$. Acesso em 28 maio 2017.

Brigham, E. F.; Houston, J. F. 1999. Fundamentos da moderna administração financeira. Campus.

Companhia Nacional de Abastecimento [CONAB]. 2017. Acompanhamento da safra: café. Disponível em: <http://www.conab.gov.br/OlalaCMS/uploads/ arquivos/17_01_17_14_51_54_boletim_cafe_-_janeiro_ de_2017.pdf > . Acesso em 28 maio 2017.

Companhia Nacional de Abastecimento [CONAB]. 2017. Acompanhamento Safra Brasileira de Café, v.3 - Safra 2016, n. 4 - Quarto Levantamento. Disponível em: <http://www.conab.gov.br/OlalaCMS/uploads/ arquivos/17_01_04_11_22_44_boletim_cafe_portugues__4o_lev_-_dez.pdf> Acesso em: 20 mar. 2017.

Centro de Estudos Avançados em Economia Aplicada [CEPEA]. 2017. Indicador de café arábica, média mensal, de janeiro de 2006 a abril de 2017.

de Arêdes, A.F.; Pereira, M.W.G. 2008. Análise econômica da produção de café arábica: um estudo de caso com simulações de Monte Carlo para sistemas de baixa e alta produtividade. Informações Econômicas, 38(4): 19-30.

Esperancini, M.S.T.; Paes, A.R. 2005. Análise de investimentos da produção de café nos sistemas irrigado e convencional, na região de Botucatu, Estado de São Paulo. Informações
Econômicas, 5(34), 52-60.

Ministério da Agricultura, Pecuária e Abastecimento [MAPA]. 2017. Indicação geográfica. Disponível em: < http://www. agricultura.gov.br/desenvolvimento-sustentavel/indicacaogeografica>. Acesso em: 30 mar. 2017.

Ministério da Agricultura, Pecuária e Abastecimento [MAPA]. 2017. Cafeicultura Brasileira. Disponível em: <http:// www.agricultura.gov.br/assuntos/politica-agricola/cafe/ cafeicultura-brasileira >. Acesso em 20 abr. 2017.

Matiello, J.B.; Santinato, R.; Garcia, A.W.R.; Almeida, S.R.; Fernandes, D.R. 2015. Cultura de Café no Brasil: manual de recomendações. Futurama, São Paulo. 572- 580p.

Noronha, J.F. 1987. Projetos agropecuários: administração financeira, orçamento e viabilidade econômica. 2 ed. Atlas, São Paulo. 269p.

Oliveira, S.J.D.M.; Veneziano, W. 2001. Aspectos econômicos da produção de café na região central do estado de Rondônia. II Simpósio de pesquisa e cafés do Brasil. Disponível em: $<$ http://www.sapc.embrapa.br/arquivos/consorcio/spcb_ anais/simposio2/economia03.pdf>.

Organização Internacional do Café [OIC]. 2017. Total production by exprorting countries. Disponível em: < http://www.ico.org/prices/po-production.pdf >. Acesso em: 12 maio 2017.

Organização Internacional do Café [OIC]. 2017. World Coffee Consumption. Disponível em: <http://www.ico.org/ prices/new-consumption-table.pdf $>$. Acesso em: 12 maio 2017. 